\title{
Chronic Obstructive Pulmonary Disease and Semantic Language Abilities
}

\author{
Konstantinos Makanikas $₫$, Georgia Andreou*, Filippos Vlachos \\ Department of Special Education, University of Thessaly, Argonafton \& Filellinon, Volos, Greece \\ Email: *andreou@uth.gr
}

How to cite this paper: Makanikas, K., Andreou, G. and Vlachos, F. (2019) Chronic Obstructive Pulmonary Disease and Semantic Language Abilities. Journal of Behavioral and Brain Science, 9, 130-143. https://doi.org/10.4236/jbbs.2019.93011

Received: December 18, 2018

Accepted: March 22, 2019

Published: March 25, 2019

Copyright $\odot 2019$ by author(s) and Scientific Research Publishing Inc. This work is licensed under the Creative Commons Attribution International License (CC BY 4.0).

http://creativecommons.org/licenses/by/4.0/

\begin{abstract}
Objective: The main aim of the present study is to evaluate the semantic language abilities of patients with Chronic Obstructive Pulmonary Disease (COPD) compared to normal group. Secondly to examine the role of hypoxemia, hypercapnia and pulmonary parameters on language scores. Method: We assessed 100 COPD patients with the use of a comprehensive battery of neurocognitive tests standardized for the Greek population, examining semantic language abilities, namely the Boston Naming Test (BNT), the Picture Peabody Vocabulary Test (PPVT) and the Controlled Oral Word Fluency Test (COWAT). Results: The results revealed that although the overall performance of our group of patients was within normal range, it was statistically significant lower compared to normal distribution on all semantic language tests. Moreover, we found that the percentile of COPD patients that performed in the deficient range was significantly higher compared to normal distribution. Further analysis of pulmonary parameters showed that Forced Expiratory Volume in $1 \mathrm{sec}$ $\left(\mathrm{FEV}_{1}, \mathrm{FEV}_{1} \%\right)$, Forced Vital Capacity (FVC, FVC\%) and $\mathrm{FEV}_{1} / \mathrm{FVC}$ were not correlated with patients' performance on the language tests. Low Partial Pressure of Oxygen in blood oxygen levels $\left(\mathrm{PaO}_{2}\right)$ was found to be able to predict the performance of patients on BNT, PPVT and semantic verbal fluency test. Abnormally elevated Partial Pressure of Carbon Dioxide $\left(\mathrm{PCaO}_{2}\right)$ in blood were not found to be related to language dysfunctions. Conclusions: Our findings indicate that our group of COPD patients is more prone to present semantic language impairments compared to normal group while low blood oxygen levels were associated with reduced performance on BNT, PPVT and semantic verbal fluency tests.
\end{abstract}

\section{Keywords}

Chronic Obstructive Pulmonary Disease (COPD), Semantic Language

Abilities, Hypoxemia, Hypercapnia 


\section{Introduction}

Chronic obstructive pulmonary disease (COPD) is a progressive disease characterized by the presence of airflow obstruction secondary to emphysema or chronic bronchitis [1]. COPD causes not a fully reversible airway limitation due to chronic inflammatory process in the pulmonary tissue that often results in breathlessness for the patients, cough [2] [3], excessive mucus production [4] and often hypoxia and hypercapnia. COPD is the fourth leading cause of death [5], behind heart disease, cancer and stroke [6]. The burden of COPD among general population is among $2.83 \%$ and $6.9 \%$ [7] [8]. Most COPD patients are between the fifth and six decade of life [2]. Tobacco smoking is the major cause of the disease, although only a minority of smokers develops clinically significant symptoms [2]. Other factors, such as indoor and outdoor air pollution, infection in childhood, asthma, genetics factors [1] [9] and occupational dust have been proposed to contribute to the development of COPD [2].

The diagnosis of COPD is based on a typical history of persistent and progressive symptoms, a risk factor for COPD and an assessment of physiologic measures of lung function [4]. The stage severity of disease is based on spirometric criteria measuring the forced expiratory volume in $1 \mathrm{sec}\left(\mathrm{FEV}_{1}\right)$ and the ratio of $\mathrm{FEV}_{1}$ to forced vital capacity (FVC) after bronchodilator administration [3] [9].

The stage severity of COPD, as noted in the 2010 update of the Global initiative for Obstructive Lung Disease (GOLD) guidelines [10] categorized as mild COPD which specified when $\mathrm{FEV}_{1}$ is $\geq 80 \%$, moderate COPD where $\mathrm{FEV}_{1}$ is among $\leq 50-<80 \%$, severe COPD defined by $\leq 30 \%-50 \% \mathrm{FEV}_{1}$ and very severe $\mathrm{COPD}$ where patients present $\mathrm{FEV}_{1}<30 \%$. Diagnosis also indicates $\mathrm{FEV}_{1} / \mathrm{FVC}<$ 0.70 [9]. A useful feature for confirmation of the diagnosis, in contrast to asthmatic patients, is that patient's lung functions do not return to normal after bronchodilator administration [2] [4]. COPD is associated with an increased mortality and morbidity implications due to extra pulmonary effects, such as lung cancer, anemia [2], pulmonary hypertension, polycythemia, peripheral oedema, cardiovascular complications, obstructive sleep apnea, chronic infections and musculoskeletal disorders (e.g. osteopenia and muscle atrophy) [2] [9] [11] as well as nutritional depletion that is caused by increased metabolism during breathiness episodes [3] [5]. Patients with COPD are significantly more likely to report symptoms such as insomnia, and difficulty in initiating and maintaining sleep [12]. Moreover, COPD patients have a higher rate of depression [13] [14] [15] and anxiety [13] [16] compared to general population.

Chronic obstructive pulmonary disease has been also found to cause general cognitive decline [17] [18] [19] especially in the cognitive functions of motor speed, attention, memory, learning and abstract reasoning [20] [21]. The presence of language dysfunctions in COPD patients is still controversial.

More specifically, research in severely and mildly hypoxic patients has documented impairments in language functions measured with semantic fluency test, namely Boston naming test, aphasia screening test or the vocabulary and similarities subscales of WAIS (Wechsler Adult Intelligence Scale) [22]. 
Mildly hypoxemic COPD patients presented mildly impaired language abilities assessed with tasks that required naming pictures verbally, writing the name of a picture without saying the name aloud, reading printed material of increasing length or repeating words [22]. Language decline have been observed even in non-hypoxemic COPD patients [23]. Other authors have noted that $88 \%$ of COPD patients presented significant decline in the vocabulary and similarities subscales of WAIS [24]. It has also been shown that $48 \%$ of COPD patients present a specific pattern of cognitive deterioration which includes a dramatic decline in verbal fluency [25].

However, there is a study which showed that from 134 severe COPD patients with mild hypoxia, only $10.4 \%$ showed sentence construction decline and $7.5 \%$ verbal fluency impairment [26].

Finally, there are studies on severe COPD patients with mild or mild-to-moderate hypoxia that found scores within normal range in vocabulary, similarities or verbal fluency tests [1] [27]. Ortapamuk \& Naldoken [28] also found that hypoxemic and non-hypoxemic COPD patients performed similar to controls in verbal production (verbal fluency test) and verbal competence (sentence construction test).

Moreover, it has been found that severe COPD patient's performance on crystallized intelligence (knowledge and vocabulary) [29] and on language (verbal fluency, sentence construction) was intact [30].

It has been suggested that the cognitive impairments in COPD patients are caused by several independent factors of lung functions and gas blood. Researches has shown that COPD severity parameters $\left(\mathrm{FEV}_{1}, \mathrm{FEV}_{1} / \mathrm{FVC}\right)$, oxygen partial pressure $\left(\mathrm{PaO}_{2}\right)$, hypercapnia $\left(\mathrm{PaCO}_{2}\right)$ [18] and oxygen desaturation $\left(\mathrm{SaO}_{2}\right)$ are related to poor cognitive processing [31].

More specifically, it has been found that Mini Mental State Examination (MMSE) scores were associated to lung volume impairments defined by FVC, $\mathrm{FEV}_{1}[26], \mathrm{FEV}_{1} / \mathrm{FVC}(\%), \mathrm{FEV}_{1}(\%), \mathrm{FVC}(\%)$ [32]. FVC was also found to be a significant predictor of working memory span [33]. In other words, the degree of pulmonary decline found to play a crucial role on the level of cognitive impairment especially in attention, psychomotor speed [34], executive functions and constructional abilities [35]. However, the majority of the researches failed to demonstrate a significant association between lung parameters and cognitive impairments [36] [37] [31].

On the other hand, there are plenty of studies that documented a significant correlation between cognitive functions and the degree of hypoxemia parameters such as arterial oxygen pressure and oxygen desaturation [38] [39]. More specifically, several studies have found that partial pressure of arterial oxygen $\left(\mathrm{PaO}_{2}\right)$ is related to complex attention, psychomotor speed, executive functions [35], constructional abilities [26] as well as immediate and delayed memory [40]. Stuss et al. found that $\mathrm{PaO}_{2}$ were highly correlated with measures of Trail Making Test $\mathrm{B}$ (TMT B), Paced Auditory Serial Addition Test (PASAT), and several of the 
memory that are relative to visual and verbal short-term memory [22].

Additionally, a correlation between memory function, attention, language, abstracting ability, psychomotor function and partial pressure of oxygen even in mildly hypoxemic COPD patients has been documented [21]. Regarding low baseline oxygen saturation $(\leq 80 \%)$, it has been shown that there is strong correlation with cognitive impairment assessed with MMSE [31] and the Bourdon-Vos test [41]. It has also been found that the risk of cognitive impairment increased with decreasing oxygen desaturation [31].

The crucial impact of blood oxygen level on cognitive dysfunctions can also be proved by the fact that non-hypoxemic patients show less cognitive deterioration [28] [42]. In other words, oxygen-depended patients have been found to achieve worse scores than controls or non-oxygen depended COPD patients on cognitive tests [18] [19] which assess verbal memory, delayed recall, attention [28], perceptual-constructional abilities and psychomotor speed [42]. Similarly, poorer performance than oxygen dependent patients, although not significant, has been found in verbal-nonverbal intelligence and in short-long term memory tests [42]. Stuss et al., also found that severely hypoxic patients obtained lower scores than did the mildly hypoxic patients on TMT B, PASAT, Digit span forward and delayed logical memory [22]. Moreover, Grant et al. showed that the rate of neuropsychological deficit rose from $27 \%$ in mild hypoxemia to $61 \%$ in severe hypoxemia [20].

Another important factor that contributes to cognitive decline is hypercapnia or hypercapnia-induced hypoventilation [25]. Özge et al., found that hypercarbia was correlated with the information-memory-concentration test and the dementia scale of Blessed dementia scale test [32]. There are studies that have found a significant correlation between high levels of $\mathrm{PaCO}_{2}$ and deficits in reaction time or logical thinking [29], in immediate and delayed memory, in complex attention, in speed of information processing, in animal-naming of verbal fluency test [22], as well as in concentration and orientation [32]. Interestingly, Stuss et al. showed that neuropsychological test scores were generally more highly correlated with $\mathrm{PaCO}_{2}$ than $\mathrm{PaO}_{2}$ [22].

Moreover, there are studies that have failed to show any association between gas blood and cognitive functions. For example, it has been found that MMSE and Blessed Dementia Scale did not correlate to hypoxemia [32]. Vos et al. failed to find any correlation between attention and daytime measures of $\mathrm{PaO}_{2}, \mathrm{SaO}_{2}$, mean $\mathrm{SaO}_{2}$ and $\mathrm{PaCO}_{2}$ after multiple regression analysis [41]. Measures of language abilities (Verbal fluency and aphasia screening test), executive functions (digit span backward, Wisconsin test) and simple attention (TMT A, digit span forward) were not generally related to arterial gas pressures [22]. $\mathrm{PO}_{2}$ levels were not correlated with measures of mental speed [36] [41]. Finally, other research did not note any correlation between arterial gas $\left(\mathrm{PaO}_{2}, \mathrm{SaO}_{2}\right)$ or lung functions $\left(\mathrm{FEV}_{1}, \mathrm{FVC}\right)$ and selective or sustain attention [37], fluid intelligence and psychomotor speed [33]. 
The literature is equivocal regarding the presence of semantic language impairments, while there are few studies that assess the role of hypoxemia, hypercapnia and pulmonary parameters or the impact of a combination of those factors on language abilities. Importantly, little is known regarding the contribution of comorbidities such as hypertension and diabetes, which are known as risk factors for cognitive decline. The present study addresses this gap in the literature, by assessing semantic language abilities in a large sample of adults with COPD and examines the impact of hypoxemia, hypercapnia and pulmonary parameters on language functions.

We hypothesize that COPD patients will present poor semantic language abilities and that there will be a correlational link between COPD characteristics and performance on semantic language tasks.

\section{Materials and Methods}

\subsection{Participants}

100 COPD patients of $69.47 \pm 8.07$ years of age and $7.12 \pm 3.28$ years of education were recruited from the Pulmonary Unit of the university hospital of Larissa, Greece during the 2013-2015. All patients who participated lived in the larger area of central Greece. The group of patients had moderate-to-severe COPD with $\mathrm{FEV}_{1} \%=49.89 \pm 19.48$ and mild hypoxia of $\mathrm{PaO}_{2}=72.72 \pm 14.70$. The criteria for recruitment were: 1 ) diagnosis of COPD according to Gold criteria 2) no episodes of exacerbation for the last 4 weeks 3) no other diagnosable lung disorder 4) individuals with cognitive deterioration (Mini Mental test score < 24), history of head injury, cerebral ischemia, encephalitis, psychiatric disorders including alcohol or drug abuse were excluded from the study. Patients whose conditions such as high blood pressure, hypercholesterolemia, cardiovascular diseases and diabetes were well controlled by medications were included.

As a comparison group, were used age- and education-adjusted standard (z) scores based on normative data validated on the Greek population, matched each COPD participant on gender, age and education level $(p>0.2)$.

\subsection{Measures}

\subsubsection{Neurocognitive Tests}

Neurocognitive testing was conducted between 9:00 am and 14:00 pm. Tests were administered in the same order to all subjects and by the same examiner, while participants were allowed to take breaks in order to minimize fatigue. Since more than one test is typically required for the assessment of lexical/semantic knowledge, the tests given were: 1) Boston Naming Test (BNT). 2) Peabody Picture Vocabulary Test-R (PPVT-R) and 3) Controlled Oral Word fluency test (COWAT).

- BNT test assesses visual confrontation naming of common objects presented as 45 black and white line drawings. Performance on this test requires recognition of the depicted object, retrieval and verbal production of the lexical entity associated with it. Access to associated semantic representations is assumed 
to take place automatically although, in principle, it is not required for task performance. Normative data are provided for healthy Greek speakers of different ages and educational backgrounds (normative sample $\mathrm{n}=468$ adults aged 50 - 84 years old) [43] [44].

- The PPVT-R test measures receptive vocabulary and includes a form consisting of 32 items. The examinee is asked to indicate on a stimulus plate which of the four drawings presented corresponds to a spoken word (noun, verb, or adjective). Due to the special response requirements of the task it is reasonable to expect that perceptual organization and decision-making ability may account for a certain amount of individual variability in performance. Norms, based on a 468 adult representative sample of Greek population, have been used on the current study [43] [44].

- The COWAT test includes two-word generation tasks 1) word generation to letter cues-phonemic task, where the participants are asked to generate words beginning with each of the following three Greek letters: X (Chi), S (Sigma), and A (Alpha), 2) word generation to category cues-semantic task, where the participants asked to generate words belonging to each of the following three semantic categories: animals, fruits and objects. Both fluency tasks are timed and participants are encouraged to generate words as fast as they can within the allocated time-limit (60" per category or letter). Normative data exist for Greek population based on 300 healthy adults aged 18 - 79 years old [45].

Raw score on all language tests were converted to $(\mathrm{z})$ scores (by the comparison with normative data according to age and education). Age and education effects on various vocabulary measures have been reported (decreasing performance with increasing age and increasing performance with increasing education) [43] [44] [45].

\subsubsection{Lung Functions and Covariates}

From the spirometry the following pulmonary parameters were measured: $\mathrm{FEV}_{1}$, $\mathrm{FEV}_{1} \%$, FVC, $\mathrm{FVC} \%, \mathrm{FEV}_{1} / \mathrm{FVC}$. Blood gas levels of $\mathrm{PaO}_{2}$ and $\mathrm{PCaO}_{2}$, as well as comorbidities like hypertension, hypercholesterolemia, cardiovascular anomalies and diabetes were also recorded. Illness duration, BMI and smoking intensity were recorded as well.

\subsection{Statistical Analyses}

Data were analyzed using IBM SPSS statistics 21 and Minitab 17.0. A probability value lower than $0.05(\mathrm{p}<0.005)$ was accepted as statistically significant. Results are given as mean \pm standard deviation (SD). After a descriptive analysis of the samples' characteristics (sociodemographic and clinical date) the following analyses were performed: Raw scores of the neuropsychological tests, for which normative data were available, were transformed into $\mathrm{Z}$ scores (controlling for gender, age and education). On a typical standard normal population, mean $=0$ and standard deviation (S.D) $=1$. Higher $\mathrm{Z}$ scores indicate better performance. $\mathrm{Z}$ 
scores $<-1.5$ were considered as indicating deficient performance. The two-tailed, one-sample t-test was used to compare differences in mean values between the group of patients and the comparison group. Differences between the patient and comparison group in the percentage of scores in the deficient range was assessed using the X2 test of proportions. Finally, the pulmonary parameters as well as blood gas levels and comorbidities which were found to present significant $r$ Pearson correlation with the scores on language tests were further analyzed by multiple regression analysis. Age, gender, and education level (in years) were included as covariates in all models.

\section{Results}

The group of COPD patients consisted of 100 obese COPD patients, mainly men of $69.47 \pm 8.07$ years of age and $7.12 \pm 3.28$ years of education. Most of the patients suffered from conditions such as high blood pressure, hypercholesterolemia, cardiovascular diseases and diabetes. The socio-demographic characteristics of the participants are summarized below in Table 1 .

The group of COPD patients performed statistically significant lower compared to the normative group in all neurolinguistics tests, namely in the semantic verbal fluency $(z=-0.94, p<0.001)$, phonemic verbal fluency $(z=-0.86, p<$ $0.001)$, BNT $(\mathrm{z}=-0.87, \mathrm{p}<0.001)$ and PPVT $(\mathrm{z}=-1.01, \mathrm{p}<0.001)$ (see Table 2$)$. However, these $Z$ scores were among the normal average $(z>-1.5)$.

A statistically significant difference was found between the patients and comparison normative group that performed in the deficient range in semantic verbal fluency ( $\mathrm{p}<0.001)$, phonemic verbal fluency ( $\mathrm{p}<0.001)$, BNT $(\mathrm{p}<0.001)$ and PPVT ( $\mathrm{p}<0.001$ ). More specifically, $40 \%$ of patients performed below the normal average in the semantic verbal fluency test, $22 \%$ in the phonemic verbal fluency, 34\% in BNT and 34\% in PPVT. Differences in mean values between the group of patients and comparison normative group are presented in Table 3.

Table 1. The socio-demographic characteristics of COPD patients.

\begin{tabular}{cc}
\hline Socio-demographic characteristics & Patients (n=100) \\
Men & $91(91 \%)$ \\
Women & $9(9 \%)$ \\
Age & $69.47 \pm 8.07(52-85)$ \\
Education in years & $7.12 \pm 3.28(1-17)$ \\
Body Mass Index (BMI) & $28.78 \pm 5.75(15-46)$ \\
Hypertension & $59(59 \%)$ \\
Hypercholesterolemia & $33(33 \%)$ \\
Cardiovascular diseases & $34(34 \%)$ \\
Diabetes & $19(19 \%)$ \\
Current smokers & $15(15 \%)$ \\
PYS & $70.19 \pm 34.53(0-150)$ \\
Disease duration in years & $5.69 \pm 4.11(1-20)$
\end{tabular}


Table 2. Performance of COPD patients on language tests compared to Greek normative data.

\begin{tabular}{ccc}
\hline Language tests & Raw Scores & Z scores \\
\hline Semantic verbal fluency & $34.47 \pm 8.86(19-61)$ & $-0.94 \pm 0.94^{\dagger}$ \\
Phonemic verbal fluency & $19.19 \pm 9.04(2-43)$ & $-0.86 \pm 0.83^{\dagger}$ \\
BNT $^{\mathrm{a}}$ & $25.79 \pm 9.12(9-44)$ & $-0.87 \pm 1.27^{\dagger}$ \\
PPVT $^{\mathrm{b}}$ & $14.39 \pm 8.56(0-32)$ & $-1.01 \pm 1.17^{\dagger}$ \\
\hline
\end{tabular}

${ }^{\dagger} \mathrm{p}<0.0001$ for the difference between the average performance of COPD patients and the performance of

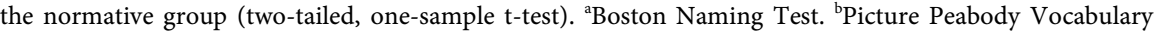
Test.

Table 3. COPD patients' percentile scores in the deficient range on language tests compared to Greek normative data.

\begin{tabular}{ccc}
\hline Language tests & COPD patients & Comparison group \\
\hline Semantic verbal fluency & $40 \%^{\dagger}$ & $6.4 \%$ \\
Phonemic verbal fluency & $22 \%^{\dagger}$ & $5.3 \%$ \\
BNT $^{\mathrm{a}}$ & $34 \%^{\dagger}$ & $7.5 \%$ \\
PPVT $^{\mathrm{b}}$ & $34 \%^{\dagger}$ & $7.2 \%$ \\
\hline
\end{tabular}

${ }^{\dagger} \mathrm{p}<0.0001$ for the rate of scores in the deficient range among patients as compared to the gender-, age-, and education level-matched normative group (Chi-Square test for proportions). ${ }^{a}$ Boston Naming Test. ${ }^{\text {b}}$ Picture Peabody Vocabulary Test.

Our research did not reveal any significant correlations between pulmonary parameters and the performance of patients in the language tests. We also failed to find any significant correlation between measured comorbidities and the language scores (see Table 4). However, we found that blood gases such as $\mathrm{PaO}_{2}$ levels were significantly correlated with the patients' performance in BTN $(r=$ $0.331, \mathrm{p}=0.001)$, PPVT $(\mathrm{r}=0.299, \mathrm{p}=0.003)$, and the semantic verbal fluency test $(\mathrm{r}=0.201, \mathrm{p}=0.048)$. No correlation was found for the phonemic verbal fluency test $(r=0.173, p=0.091)$. Oxygen desaturation index was found to be correlated only with the patients' performance in BTN $(r=0.230, p=0.023)$, PPVT $(r=0.259, p=0.011)$. On the other hand, high levels of carbon dioxide in blood was not found to be correlated with the performance in the language tests (see Table 5).

A linear multiple regression analysis of the previous parameters showed that the association between the low $\mathrm{PaO}_{2}$ levels and patients' performance reached significance in BNT $\left(\mathrm{R}^{2}=0.402, \mathrm{p}=0.001\right)$, PPVT $\left(\mathrm{R}^{2}=0.492, \mathrm{p}=0.003\right)$ and the semantic verbal fluency test $\left(\mathrm{R}^{2}=0.322, \mathrm{p}=0.048\right) . \mathrm{SaO}_{2}$ was also found that it could predict the patients' score on BNT $\left(\mathrm{R}^{2}=0.364, \mathrm{p}=0.023\right)$ and PPVT $\left(\mathrm{R}^{2}=0.479, \mathrm{p}=0.011\right)$. The association between the levels of $\mathrm{PCO}_{2}$ and patients' performance in the language tests did not reach significance. The results of the regression analysis are presented in Table 6.

\section{Discussion}

In the present study we evaluated the semantic language abilities of COPD patients 
Table 4. Correlation analysis between COPD lung parameters, comorbidities and performance on language tests.

\begin{tabular}{ccccccccc}
\hline & \multicolumn{2}{c}{ BTN $^{\mathrm{a}}$} & \multicolumn{2}{c}{ PPVT $^{\mathrm{b}}$} & \multicolumn{2}{c}{ Semantic test } & \multicolumn{2}{c}{ Phonemic test } \\
\hline & $\mathrm{r}$ & $\mathrm{p}$ Value & $\mathrm{r}$ & $\mathrm{p}$ Value & $\mathrm{r}$ & $\mathrm{p}$ Value & $\mathrm{r}$ & $\mathrm{p}$ Value \\
\hline Disease duration & 0.022 & 0.834 & -0.062 & 0.547 & 0.048 & 0.644 & 0.013 & 0.897 \\
FEV1 & 0.172 & 0.092 & 0.114 & 0.267 & 0.135 & 0.186 & 0.194 & 0.057 \\
FEV1\% & 0.103 & 0.317 & 0.044 & 0.669 & 0.084 & 0.415 & 0.172 & 0.092 \\
FVC & 0.189 & 0.063 & 0.113 & 0.271 & 0.163 & 0.110 & 0.142 & 0.164 \\
FVC\% & 0.137 & 0.181 & 0.031 & 0.763 & 0.120 & 0.240 & 0.117 & 0.252 \\
FEV /FVC & -0.001 & 0.992 & 0.022 & 0.829 & 0.003 & 0.980 & 0.170 & 0.096 \\
Hypertension & 0.010 & 0.919 & 0.020 & 0.845 & -0.070 & 0.496 & -0.061 & 0.551 \\
Diabetes & 0.077 & 0.456 & -0.006 & 0.953 & -0.020 & 0.844 & -0.019 & 0.852 \\
Cardiovascular Disease & 0.140 & 0.170 & 0.183 & 0.072 & 0.101 & 0.327 & 0.111 & 0.278 \\
Hypercholesterolemia & -0.135 & 0.186 & 0.043 & 0.678 & 0.042 & 0.684 & 0.027 & 0.793 \\
PYS & 0.089 & 0.386 & 0.029 & 0.775 & -0.072 & 0.486 & -0.002 & 0.984 \\
BMI & 0.023 & 0.823 & -0.013 & 0.897 & 0.149 & 0.144 & 0.119 & 0.244 \\
\hline
\end{tabular}

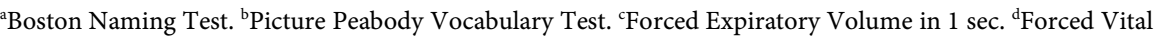
Capacity.

Table 5. Correlation analysis between gas blood and scores on language tests.

\begin{tabular}{cccccccccc}
\hline & \multicolumn{2}{c}{ BNT $^{\text {a }}$} & \multicolumn{2}{c}{ PPVT $^{\mathrm{b}}$} & \multicolumn{2}{c}{$\begin{array}{c}\text { Semantic verbal } \\
\text { fluency }\end{array}$} & \multicolumn{2}{c}{$\begin{array}{c}\text { Phonemic verbal } \\
\text { fluency }\end{array}$} \\
\hline & $\mathrm{r}$ & $\mathrm{p}$ Value & $\mathrm{r}$ & $\mathrm{p}$ Value & $\mathrm{r}$ & $\mathrm{p}$ Value & $\mathrm{r}$ & $\mathrm{p}$ Value \\
\hline Daytime $\mathrm{SO}_{2}$ & $\mathbf{0 . 2 3 0 ^ { * }}$ & 0.023 & $\mathbf{0 . 2 5 9 ^ { * }}$ & 0.011 & 0.167 & 0.102 & 0.042 & 0.681 \\
$\mathrm{PO}_{2}$ & $\mathbf{0 . 3 3 1 ^ { * * }}$ & 0.001 & $\mathbf{0 . 2 9 9 ^ { * * }}$ & 0.003 & $\mathbf{0 . 2 0 1}$ & 0.048 & 0.173 & 0.091 \\
$\mathrm{PCO}_{2}$ & -0.136 & 0.184 & -0.128 & 0.212 & -0.044 & 0.665 & -0.067 & 0.517 \\
\hline
\end{tabular}

Bold entries in the table indicate a significant statistical correlation. ${ }^{*}$ Significant Statistical correlation with p-value of $\leq 0.05 .{ }^{*}$ Significant Statistical correlation with p-value of $<0.01$. ${ }^{a}$ Boston Naming Test. ${ }^{b}$ Picture Peabody Vocabulary Test. ${ }^{a}$ Boston Naming Test. ${ }^{b}$ Picture Peabody Vocabulary Test. ${ }^{~}$ Daytime desaturation index. ${ }^{\mathrm{d}}$ Partial pressure of oxygen. ${ }^{\mathrm{e} P a r t i a l}$ pressure of carbon dioxide.

Table 6. Linear multiple regression analysis between oxygen desaturation index, blood gas level, pulmonary parameters and language tests.

\begin{tabular}{ccccc}
\hline \multirow{2}{*}{$\begin{array}{c}\text { Independent } \\
\text { Variables }\end{array}$} & $\mathrm{BNT}^{\mathrm{a}}$ & \multicolumn{4}{c}{ Dependent Variables } \\
\cline { 2 - 5 } & $\mathrm{R}^{2}=\mathbf{0 . 3 6 4}$, & $\mathbf{R}^{2}=\mathbf{0 . 4 7 9}$, & $\begin{array}{c}\text { Semantic verbal } \\
\text { fluency }\end{array}$ & $\begin{array}{c}\text { Phonemic verbal } \\
\text { fluency }\end{array}$ \\
\hline $\mathrm{SaO}_{2}$ & $\mathrm{p}=\mathbf{0 . 0 2 3}$ & $\mathrm{p}=\mathbf{0 . 0 1 1}$ & $\mathrm{R}^{2}=0.313, \mathrm{p}=0.102$ & $\mathrm{R}^{2}=0.320, \mathrm{p}=0.681$ \\
& $\mathrm{R}^{2}=\mathbf{0 . 4 0 2 ,}$ & $\mathbf{R}^{2}=\mathbf{0 . 4 9 2}$, & $\mathbf{R}^{2}=\mathbf{0 . 3 2 2 ,}$ & $\mathrm{R}^{2}=0.339, \mathrm{p}=0.091$ \\
$\mathrm{PaO}_{2}$ & $\mathrm{p}=\mathbf{0 . 0 0 1}$ & $\mathrm{p}=\mathbf{0 . 0 0 3}$ & $\mathrm{p}=\mathbf{0 . 0 4 8}$ & \\
$\mathrm{PCaO}_{2}$ & $\mathrm{R}^{2}=0.341, \mathrm{p}=0.184 \mathrm{R}^{2}=0.451, \mathrm{p}=0.212$ & $\mathrm{R}^{2}=0.295, \mathrm{p}=0.665 \mathrm{R}^{2}=0.322, \mathrm{p}=0.517$ \\
$\mathrm{FEV}_{1}$ & $\mathrm{R}^{2}=0.348, \mathrm{p}=0.092$ & $\mathrm{R}^{2}=0.449, \mathrm{p}=0.267$ & $\mathrm{R}^{2}=0.307, \mathrm{p}=0.186 \mathrm{R}^{2}=0.344, \mathrm{p}=0.057$ \\
$\mathrm{FVC}$ & $\mathrm{R}^{2}=0.353, \mathrm{p}=0.063$ & $\mathrm{R}^{2}=0.449, \mathrm{p}=0.271$ & $\mathrm{R}^{2}=0.312, \mathrm{p}=0.110$ & $\mathrm{R}^{2}=0.333, \mathrm{p}=0.164$ \\
\hline
\end{tabular}

Bold entries in the table indicate a significant statistical correlation. ${ }^{*}$ Significant Statistical correlation with p-value of $\leq 0.05 .{ }^{*}$ Significant Statistical correlation with $\mathrm{p}$-value of $<0.01$. ${ }^{\mathrm{a}}$ Boston Naming Test. ${ }^{b}$ Picture

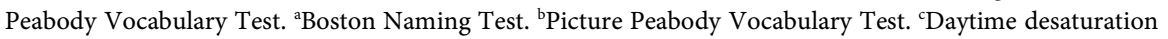
index. ${ }^{\mathrm{d} P a r t i a l}$ pressure of oxygen. ${ }^{\mathrm{e} P a r t i a l}$ pressure of carbon dioxide. ${ }^{\mathrm{f}}$ Forced Expiratory Volume in $1 \mathrm{sec}$. ${ }^{\mathrm{g}}$ Forced Vital Capacity. 
and we analyzed the impact of pulmonary parameters, comorbidities as well as blood gas levels on the patients' language abilities. It has been found that the group of COPD patients scored significantly lower compared to the normative group on language tasks assessing availability and efficiency of access/retrieval of lexical/semantic representations. This finding extends previous reports focusing on verbal fluency tasks [46] [47] [48], and suggests that performance in untimed lexical/semantic tasks may also be affected in COPD. Notably, the percentage of patients scoring in the deficient range in verbal fluency tasks (22\% - 40\%) was close to that reported in a previous study [25]. However, another research has found that $88 \%$ of COPD patients presented low scores on tests such as the vocabulary and similarities subscales of WAIS [24].

Furthermore, we assessed the association between COPD severity, as indexed by FEV1 pulmonary parameter and FEV1/FVC, and language scores. We found that pulmonary parameters such as the $\mathrm{FEV}_{1}$ and the $\mathrm{FEV}_{1} / \mathrm{FVC}$ do not correlate with the patient's performance on language tests, a result which has also been found by previous researches [22] [31] [36] [37]. On the other hand, we found some correlational link between oxygen blood gas levels and language performance on BNT, PPVT and semantic verbal fluency test. These tests assess the semantic/lexical representations while the phonemic verbal fluency test evaluates more the executive functions and less the semantic language abilities. Our results support earlier findings that hypoxemia affects negatively the cognitive abilities of COPD patients [20] [28] [39]. On the other hand, in contrast to many studies [22] [29] our findings failed to demonstrate direct associations between performance in semantic language tests and high levels of $\mathrm{PaCO}_{2}$. Moreover, illness duration, BMI and smoking intensity was not found to be related with semantic language impairments in our group of patients.

However, there are some limitations in our study. Smoking history has been assessed only by asking the participants retrospectively which means that there may be some kind of inaccuracy concerning this data. Moreover, the participants of the normative group were not assessed for their lung function and arterial blood gas and therefore latent COPD patients might have erroneously been included in the normative group. However, this misclassification would have led to smaller differences rather than significant false results.

It should be noted that the precise mechanisms that were responsible for the neurocognitive impairments displayed by COPD patients remain unknown, since several factors may have contributed to these findings. In particular, the present study was not designed to address the pathophysiological substrate of language impairment, which may involve a wide range of potentially interrelated processes such as microvascular cerebral pathology [49], and changes in systemic hemodynamics and inflammation [50].

In terms of clinical relevance, since language impairments are not easily observed by patients and their partners, it seems to be important to inform patients on the possible cognitive dysfunctions associated with COPD. 


\section{Conclusion}

The present study reveals that COPD may affect language functions, and especially those that involve efficient retrieval of lexical/semantic representations. Overall oxygen blood gas levels emerged as the most important factor that affected semantic language test performance. For that reason, the effects of early diagnosis and medical treatment of COPD on semantic language performance should be further studied.

\section{Acknowledgements}

We would like to thank the staff of the pulmonary department of the university hospital of Larisa where the pulmonary and neuropsychological assessment took place.

\section{Conflicts of Interest}

The authors declare no financial or personal conflict of interest.

\section{References}

[1] Crews, W.D., Jefferson, A.L., Bolduc, T., Elliott, J.B., Ferro, N.M., Broshek, D.K., Bart, J.T. and Robbins, M.K. (2001) Neuropsychological Dysfunction in Patients Suffering from End-Stage Chronic Obstructive Pulmonary Disease. Archives of Clinical Neuropsychology, 16, 643-652. https://doi.org/10.1093/arclin/16.7.643

[2] Cazzola, M., Donner, C. and Hanania, N.A. (2008) One Hundred Years of Respiratory Medicine Chronic Obstructive Pulmonary Disease (COPD)-Republished. Respiratory Medicine, 4, 8-25.

[3] Russell, R. and Norcliffe, J. (2008) Chronic Obstructive Pulmonary Disease: Management of Chronic Disease. Medicine, 36, 218-222. https://doi.org/10.1016/j.mpmed.2008.01.010

[4] Calverley, P.M.A. and Walker, P. (2003) Chronic Obstructive Pulmonary Disease. Lancet, 362, 1053-1061. https://doi.org/10.1016/S0140-6736(03)14416-9

[5] Petty, T.L. (2003) Definition, Epidemiology, Course, and Prognosis of COPD. Clinical Cornerstone, 5, 1-10. https://doi.org/10.1016/S1098-3597(03)90003-2

[6] Owens, R.L. and Malhotra, A. (2010) Sleep-Disordered Breathing and COPD: The Overlap Syndrome. Respiratory Care, 55, 1333-1344.

[7] Cazzola, M., Puxeddu, E., Bettoncelli, G., Novelli, L., Segreti, A., Cricelli, C. and Calzetta, L. (2011) The Prevalence of Asthma and COPD in Italy: A Practice-Based Study. Respiratory Medicine, 105, 386-391. https://doi.org/10.1016/j.rmed.2010.09.022

[8] Soriano, J., Maier, W., Egger, P., Visick, G., Thakrar, B., Sykes, J. and Pride, N. (2000) Recent Trends in Physician Diagnosed COPD in Women and Men in the UK. Thorax, 55, 789-794. https://doi.org/10.1136/thorax.55.9.789

[9] Mannino, D.M. and Buist, A.S. (2007) Global Burden of COPD: Risk Factors, Prevalence, and Future Trends. Lancet, 370, 765-773. https://doi.org/10.1016/S0140-6736(07)61380-4

[10] Global Initiative for Chronic Obstructive Lung Disease. Global Strategy for the Diagnosis, Management, and Prevention of Chronic Obstructive Pulmonary Disease-Updated 2010. 
[11] Coultas, D.B. and Davis, K. (2009) Hidden Realities of COPD among the Very Old. European Respiratory Monograph, 43, 77-89.

[12] Valipour, A., Lavie, P., Lothaller, H., Mikulic, I. and Burghuber, O.C. (2011) Sleep Profile and Symptoms of Sleep Disorders in Patients with Stable Mild to Moderate Chronic Pulmonary Disease. Sleep Medicine, 12, 367-372. https://doi.org/10.1016/j.sleep.2010.08.017

[13] Hynninen, K.M.J., Breitve, M.H., Alice, B., Wiborg, A.B., Pallesen, S. and Nordhus, I.H. (2005) Psychological Characteristics of Patients with Chronic Obstructive Pulmonary Disease: A review. Journal of Psychosomatic Research, 59, 429-443. https://doi.org/10.1016/j.jpsychores.2005.04.007

[14] Wilson, I. (2006) Depression in the Patients with COPD. International Journal of COPD, 1, 61-64. https://doi.org/10.2147/copd.2006.1.1.61

[15] Borak, J., Sliwinski, P., Tobiasz, M., Gorecka, D. and Zielinski, J. (1996) Psychological Status of COPD Patients before and after One Year of Long-Term Oxygen Therapy. Monaldi Archives for Chest Disease, 51, 7-11.

[16] Emery, C.F., Schein, R.L., Hauck, E.R. and Macintyre, N.R. (1998) Psychological and Cognitive Outcomes of a Randomized Trial of Exercise among Patients with Chronic Obstructive Pulmonary Disease. Health Psychology, 17, 232-240. https://doi.org/10.1037/0278-6133.17.3.232

[17] Antonelli-Incalzi, R., Corsonello, A., Trojano, L., Pedone, C., Acanfora, D., Spada, A., Izzo, O. and Rengo, F. (2007) Screening of Cognitive Impairment in Chronic Obstructive Pulmonary Disease. Dementia and Geriatric Cognitive Disorders, 23, 264-270. https://doi.org/10.1159/000100773

[18] Borson, S., Scanlan, J., Friedman, S., Zuhr, E., Fields, J., Aylward, E., Mahurin, R., Richards, T., Anzai, Y., Yukawa, M. and Yeh, S. (2008) Modeling the Impact of COPD on the Brain. International Journal of Chronic Obstructive Pulmonary Disease, 3, 429-434. https://doi.org/10.2147/COPD.S2066

[19] Hung, W.W., Wisnivesky, J.P., Siu, A.L. and Ross, J.S. (2009) Cognitive Decline among Patients with Chronic Obstructive Pulmonary Disease. American Journal of Respiratory and Critical Care Medicine, 180, 134-137. https://doi.org/10.1164/rccm.200902-0276OC

[20] Grant, I., Heaton, R.K., McSweeny, A.J., Adams, K.M. and Timms, RM. (1982) Neuropsychologic Findings in Hypoxemic Chronic Obstructive Pulmonary Disease. Archives of Internal Medicine, 142, 1470-1476. https://doi.org/10.1001/archinte.1982.00340210062015

[21] Prigatano, G.P., Wright, E.C. and Levin, D. (1984) Quality of Life and Its Predictors in Patients with Mild Hypoxemia and Chronic Obstructive Pulmonary Disease. Archives of Internal Medicine, 144, 1613-1619. https://doi.org/10.1001/archinte.1984.00350200121018

[22] Stuss, D.T., Peterkin, I., Guzman, D.A., Guzman, C. and Troyer, A.K. (1997) Chronic Obstructive Pulmonary Disease: Effects of Hypoxia on Neurological and Neuropsychological Measures. Journal of Clinical and Experimental Neuropsychology, 19, 515-524. https://doi.org/10.1080/01688639708403741

[23] Antonelli-Incalzi, R., Marra, C., Giordano, A., Calcagni, M.L., Cappa, A., Basso, S., Pagliari, G. and Fuso. L. (2003) Cognitive Impairment in Chronic Obstructive Pulmonary Disease-A Neuropsychological and Spect Study. Journal of Neurology, 250, 325-332. https://doi.org/10.1007/s00415-003-1005-4

[24] Kass, I., Dyksterhuis, J.E., Rubin, H. and Patil, K.D. (1975) Correlation of Psychophysiologic Variables with Vocational Rehabilitation Outcome in Patients with 
Chronic Obstructive Pulmonary Disease. Chest, 67, 433-440.

https://doi.org/10.1378/chest.67.4.433

[25] Antonelli-Incalzi, R., Gemma, A., Marra, C., Muzzolon, R., Capparella, O. and Carbonin, P. (1993) Chronic Obstructive Pulmonary Disease. An Original Model of Cognitive Decline. The American Review of Respiratory Disease, 148, 418-424. https://doi.org/10.1164/ajrccm/148.2.418

[26] Antonelli-Incalzi, R., Corsonello, A., Pedone, C., Trojano, L., Acanfora, D., Spada, A., Izzo, O. and Rengo, F. (2006) Drawing Impairment Predicts Mortality in Severe COPD. Chest, 130, 1687-1694. https://doi.org/10.1378/chest.130.6.1687

[27] Kozora, E., Rojas, S. and Make, B. (1998) Self-Report of Cognitive Functioning in Patients with Chronic Obstructive Pulmonary Disease. Archives of Clinical Neyropsychology, 13, 116-117. https://doi.org/10.1093/arclin/13.1.116a

[28] Ortapamuk, H. and Naldoken, S. (2006) Brain Perfusion Abnormalities in Chronic Obstructive Pulmonary Disease: Comparison with Cognitive Impairment. Annals of Nuclear Medicine, 20, 99-106. https://doi.org/10.1007/BF02985621

[29] Klein, M., Gauggel, S., Sachs, G. and Pohl, W. (2010) Impact of Chronic Obstructive Pulmonary Disease (COPD) on Attention Functions. Respiratory Medicine, 104, 52-60. https://doi.org/10.1016/j.rmed.2009.08.008

[30] Antonelli-Incalzi, R., Corsonello, A., Pedone, C., Trojano, L., Acanfora, D., Spada, A., D’addio, G., Maestri, R., Rengo, F. and Rengo, G. (2009) Heart Rate Variability and Drawing Impairment in Hypoxemic COPD. Brain and Cognition, 70, 163-170. https://doi.org/10.1016/j.bandc.2009.01.010

[31] Thakur, N., Blanc, P., Julian, L., Yelin, E.H., Katz, P.P., Sidney, S., Iribarren, C. and Eisner, M.D. (2010) COPD and Cognitive Impairment: The Role of Hypoxemia and Oxygen Therapy. International Journal of Chronic Obstructive Pulmonary Disease, 5, 263-269.

[32] Özge, C., Özge, A. and Unal, O. (2006) Cognitive and Functional Deterioration in Patients with Severe COPD. Behavioural Neurology, 17, 121-130. https://doi.org/10.1155/2006/848607

[33] Etnier, J.L., Johnston, R., Dagenbach, D., Polland, R.J., Rajeski, W.J. and Berry, M. (1999) The Relationship among Pulmonary Function, Aerobic Fitness, and Cognitive Functioning in Older COPD Patients. Chest, 116, 953-960. https://doi.org/10.1378/chest.116.4.953

[34] Richards, M., Strachan, D., Hardy, R., Kuh, D. and Wadsworth, M. (2005) Lung Function and Cognitive Ability in a Longitudinal Birth Cohort Study. Psychosomatic Medicine, 67, 602-608. https://doi.org/10.1097/01.psy.0000170337.51848.68

[35] Fix, A.J., Golden, C.J., Daughton, D., Kass, I. and Bell, C.W. (1982) Neuropsychological Deficits among Patients with Chronic Obstructive Pulmonary Disease. The International Journal of Neuroscience, 16, 99-105. https://doi.org/10.3109/00207458209147610

[36] Liesker, J.W., Postmaa, D.S., Beukema, R.J., Hacken, N.H.T., Molen, T., Riemersma, R.A., Zomeren, H. and Kerstjens, M.H. (2004) Cognitive Performance in Patients with COPD. Respiratory Medicine, 98, 351-356. https://doi.org/10.1016/j.rmed.2003.11.004

[37] Orth, M., Kotterba, S., Duchna, K., Widdig, W., Rasche, K., Duchna, H.W. and Schultze-Werninghaus, G. (2006) Cognitive Deficits in Patients with Chronic Obstructive Pulmonary Disease (COPD). Pneumologie, 60, 593-599. https://doi.org/10.1055/s-2006-944251

[38] Kirkil, G., Tug, T., Ozel, E., Bulut, S., Tekatas, A. and Muz, M.H. (2007) The Evalu- 
ation of Cognitive Functions with P300 Test for Chronic Obstructive Pulmonary Disease Patients in Attack and Stable Period. Clinical Neurology and Neurosurgery, 109, 553-560. https://doi.org/10.1016/j.clineuro.2007.03.013

[39] Salik, Y., Ozalevli, S. and Cimrin, A.H. (2007) Cognitive Function and Its Effects on the Quality of Life Status in the Patients with Chronic Obstructive Pulmonary Disease (COPD). Archives of Gerontology and Geriatrics, 45, 273-280. https://doi.org/10.1016/j.archger.2006.12.002

[40] Huppert, F.A. (1982) Memory Impairment Associated with Chronic Hypoxia. Tho$\operatorname{rax}, 37,858-860$. https://doi.org/10.1136/thx.37.11.858

[41] Vos, P.J.E., Folgering, H.T.M. and Herwaarden, C.L.A. (1995) Visual Attention in Patients with Chronic Obstructive Pulmonary Disease. Biological Psychology, 41, 295-305. https://doi.org/10.1016/0301-0511(95)05140-6

[42] Krop, H.D., Block, A.J. and Cohen, E. (1973) Neuropsychologic Effects of Continuous Oxygen Therapy in Chronic Obstructive Pulmonary Disease. Chest, 64, 317-322. https://doi.org/10.1378/chest.64.3.317

[43] Simos, P., Kasselimis, D. and Mouzaki, A. (2008) Adult Norms for Vocabulary Measures in Greek: I. Age, Gender, and Education Effects. Aphasiology, 23, 1-24.

[44] Simos, P., Kasselimis, D. and Mouzaki, A. (2009) Adult Norms for Vocabulary Measures in Greek: II. Derivation of Short Forms and Effects of Health Status. Aphasiology, 25, 1-19. https://doi.org/10.1080/02687030802480478

[45] Kosmidis, M.H., Vlahou, C.H. and Panagiotaki, P. (2004) The Verbal Fluency Task in the Greek Population: Normative Date, and Clustering and Switching Strategies. Journal of International Neuropsychological Society, 10, 164-172. https://doi.org/10.1017/S1355617704102014

[46] Emery, C.F., Green, M.R. and Suh, S. (2008) Neuropsychiatric Function in Chronic Lung Disease: The Role of Pulmonary Rehabilitation. Respiratory Care, 53, 1208-1216.

[47] Emery, C.F., Honn, V.J., Frid, D.J., Lebowitz, K.R. and Diaz, P.T. (2001) Acute Effects of Exercise on Cognition in Patients with Chronic Obstructive Pulmonary Disease. American Journal of Respiratory and Critical Care Medicine, 164, 1624-1627. https://doi.org/10.1164/ajrccm.164.9.2104137

[48] Kozora, E. and Make, J.B. (2000) Cognitive Improvement Following Rehabilitation in Patients with COPD. Chest, 117, 249S. https://doi.org/10.1378/chest.117.5_suppl_1.249S

[49] Aloia, M.S., Arnedt, J.T., Davis, J.D., Riggs, R.L. and Byrd, D. (2004) Neuropsychological Sequel of Obstructive Sleep Apnea-Hypopnea Syndrome: A Critical Review. Journal of the International Neuropsychological Society, 10, 772-785. https://doi.org/10.1017/S1355617704105134

[50] Andreou, G., Vlachos, F. and Makanikas, K. (2014) Effects of Chronic Obstructive Pulmonary Disease and Obstructive Sleep Apnea on Cognitive Function: Evidence for a Common Nature. Sleep Disorders, 14, Article ID: 768210.

https://doi.org/10.1155/2014/768210 